\title{
The Role of Silver Diamine Fluoride in Reducing Caries Activity in Children and the Elderly: A review
}

\author{
Nalini Doppalapudi ${ }^{*}$ and Ravindra Kumar Burugapalli ${ }^{2}$ \\ ${ }^{1}$ Community Health Center INC, New London, USA \\ ${ }^{2}$ Mericare, Meriden, USA \\ *Corresponding author: Nalini Doppalapudi Community Health Center INC,New London, CT, United States
}

\begin{abstract}
Silver Diamine Fluoride (SDF) has created immense interest among the dental community in recent times because of its potential to generate remineralization and its non-invasive nature of application in managing dental caries. Therefore, the authors have taken the initiative to review existing literature on SDF critically. The critical overview of the global evidence to date has been put together to provide insights into SDF. A literature search was performed in Medline database without date restrictions using relevant keywords for the synthesis of data. The bibliographic information was gathered, and relevant full-length articles were obtained for the critical overview. This overview critically summarizes the existing, published evidence for the efficacy and safety of SDF, discusses its mechanisms of action, and lays down the recommendations for its use. It also presents its indications, contraindications, risks and benefits. The overview describes caries prevention in children and elderly patients. SDF can be effectively used for caries prevention among groups such as pediatric, geriatric, special health care needs, and those that are limited in access to oral health care
\end{abstract}

Keywords: Minimally Invasive Dentistry; Primary Teeth; Silver Compounds; Dental Caries

\section{Introduction}

Dental caries is one of the most common diseases, affecting the world's population at large regardless of gender, age, and ethnicity [1]. Early Childhood Caries (ECC) affects a great majority of preschool children throughout the world. About $80 \%$ of the ECC is found in children from low income families, and it is a serious global health problem [2]. Around 35\% of people have untreated caries in their permanent dentition with the numbers increasing in children, proving to be a challenging dental disease for clinicians [2]. Various approaches for caries prevention have emerged based on the evidence reported. These strategies of prevention in children and the elderly require significant financial investment and infrastructure and depend heavily on the availability of the oral health care workforce [2]. However, improved preventive efforts and treatment strategies for children and the elderly population remain sparse as both age groups need special attention. SDF is being used to arrest dental caries in various parts of the world [35]. In 2015, Elevate oral care introduced "Advantage Arrest ${ }^{\mathrm{TM}}$ Silver diamine fluoride 38\%" to the dental market in North America [6]. The chemistry and nomenclature for SDF (AgFH6N2) describes it as Silver diamine fluoride, a metal ammine complex of silver fluoride [6]. Silver material with a nanoparticle size has been recently developed, which retains the antimicrobial properties of the larger sized silver ion material without its undesired discoloring effects [7]. In the United States, the Food and Drug Administration approved SDF as fluoride to manage hypersensitive teeth [5]. Off-label use of SDF for prevention of caries is now permissible and appropriate under U.S. law [7]. In 2016 a CDT code was also approved for medicaments used in arresting caries to help with 
documentation and billing $[8,9]$. A recent survey on the use of SDF showed that it is being adopted in training programs of graduate pediatric dentistry, and the majority are ready to incorporate it into their clinics and teaching curricula [10]. A longitudinal, pragmatic, cluster-randomized, single-blind, non-inferiority trial is going on in the state of New Hampshire in low-income rural children of public elementary schools from 2018 to 2023. This study is aimed to compare SDF's effectiveness in prevention and arrest of dental caries with a secondary objective to compare cost-effectiveness $[11,12]$.

\section{SDF's history and mechanism of action}

The use of silver nitrate can be traced back to around $1000 \mathrm{AD}$ in Japan, when it was used to blacken teeth for cosmetic purposes. Silver compounds like silver nitrate, silver sutures and silver foil have been used in the prevention and treatment of surgical, ocular, and dental infections [13]. SDF is a clear, odorless liquid used for the desensitization of non-carious lesions [14]. 38\% topical SDF was shown to be safe and was well tolerated in healthy adult volunteers [15]. A $38 \%$ SDF equivalent to $44,800 \mathrm{ppm}$ fluoride ions solution is used to arrest caries of primary teeth in young non-compliant children $[2,3,16,17]$. In vitro studies of SDF indicate bactericidal action against $S$. mutans $[18,19]$. SDF slows down the demineralization of dentine [20-23]. Its clinical success could be credited to this dual action [20]. SDF is also effective in reducing the numbers of S. mutans in dentinal tubules [24]. Antifungal potency of SDF against C. albicans, C. krusei and C. glabrata was demonstrated [25]. Many in vitro studies proved the effectiveness of SDF in inhibiting dentine demineralization and collagenases such as matrix metalloproteinases and cysteine cathepsins thus preventing dentine collagen degradation [26-28]. Silver inhibits bacterial growth by interacting with the bacterial cell membrane and bacterial enzymes. Doping of silver onto hydroxyapatite has an antibacterial effect on silver doped hydroxyapatite [28]. Fluoride forms fluor hydroxyapatite and enhances mineral formation with reduced solubility [28]. The elevated levels of calcium and phosphorus significantly increase microhardness [28]. In an alkaline solution silver and fluoride combine synergistically and arrest dentinal caries [28]. Post intervention using 38\% SDF showed reduced relative abundance of microbial profiles of plaque biofilms of cervical caries in some acid producing species $[29,30]$.

The histologic examination of the primary human tooth with deep caries and six months after being treated with SDF showed the formation of tertiary dentin, a flattened odontoblastic layer, dentinal tubules with silver deposits up to a depth of $1 \mathrm{~mm}$ without any bacteria, a pulp without marked inflammation, and no carious pulp exposure [31]. In vitro study on primary dentition showed that SDF is efficient in preventing the demineralization of teeth [32]. Studies indicate the formation of silver-enriched barriers surrounding the carious lesions [33]. Spectrum analysis of the lesions treated with SDF identified the following elements silver, calcium, carbon, oxygen, phosphorus, and chlorine [33]. Additionally, zinc, sodium, aluminum, magnesium, sulfur, fluorine, and silicon were detected as the minor elements. Such observations provide sources of new evidence for defining the mode of action of SDF in arresting caries [33]. SDF at a concentration of 38\%, 30\%, and $12 \%$ inhibits the activity of cathepsin $\mathrm{B}$ and $\mathrm{K}$ that causes caries progression through collagen degradation [34]. Ex-vivo study after SDF application showed highly remineralized zone rich in calcium and phosphate on the arrested cavitated lesion which protects the collagen $[23,35]$. Fluor hydroxyapatite was produced when SDF reacted with calcium and phosphate ions. This is one of the key mechanisms that brought about the arrest of caries by reducing the solubility of the region [36]. SDF was suggested as a potential indirect pulp capping material due to its remineralizing efficacy [36]. SDF's use as a drill less dental filling has been mentioned [37-40].

\section{SDF in caries prevention and reduction}

Atraumatic management of carious lesions by way of using minimally invasive techniques have been proposed [9,27,41-44]. A prospective, controlled clinical trial was conducted in Chinese preschool kids to study the effectiveness of topical fluoride applications in arresting dentinal caries by using a solution containing 44,800 ppm of SDF and 22,600 ppm of NaF annually [45]. SDF was found to be effective in arresting dentinal caries in primary anterior teeth in pre-school children [46] and secondary caries prevention in primary teeth [40]. Two double blind randomized placebocontrolled superiority trials with two parallel groups showed the application of topical 38\% SDF to be effective and safe in arresting cavities in preschool children $[47,48]$. A prospective controlled clinical trial on the deciduous teeth among six-year-old school children found that SDF reduced caries in primary teeth and first permanent molars [49]. In cases where restorative treatment for primary teeth was not available 38\% SDF proved effective [50]. Randomized clinical trials in preschool children showed the arrest of active dentine caries and suggested an application frequency of six to twelve months among children with poor oral hygiene [48,5158]. Many systematic reviews were performed to understand the effectiveness of SDF in comparison to fluoride varnish for prevention of caries and concluded that SDF is more effective than fluoride varnish and proved to be a valuable caries preventive intervention [13,59-63].

SDF is a safe, efficient, and effective caries preventive agent and can fulfill the criteria of the WHO millennium goals as well as US institute of medicine's standards for $21^{\text {st }}$-century medical care $[5,13,52,62]$. Many meta-analyses were performed to understand the efficacy of SDF in the prevention of caries progression [64-72]. Chu CH. et al. [4] found that 38\% SDF arrested dentine caries, and the overall proportion of arrested caries was $65.9 \%$ among five studies. Other systematic reviews showed $38 \%, 30 \%$ and $10 \%$ of 
SDF to arrest caries in primary teeth and showed $81 \%$ of arrested caries [65-67]. Chibinski et al. [68] found that the use of SDF is $89 \%$ more effective in arresting caries than other treatments or placebos [68]. Gugnani N et al. [69] found that 38\% SDF is effective in arresting active dentine caries [69-72]. The study of [13] has shown limited quality patient-oriented evidence [73]. SDF treatment is a promising strategy in managing dental caries in young children and those with special needs [65,74-77]. SDF should form an essential addition to every dentist's armamentarium [61]. SDF is more effective in controlling caries in children than atraumatic restorative treatment or fluoride varnish [78,79]. Chu $\mathrm{CH}$ et al. reported a successfully treated case of severe rampant dental decay in a young teenager using SDF [80]. A study on the stability of silver and fluoride cautioned clinicians to replace the cap immediately and use it as soon as it is dispensed [81]. Because the drops are larger than expected, and each drop delivers higher quantities of silver and fluoride than expected [81].

\section{Caries prevention in the elderly with SDF}

This part of the review also considered caries prevention in the elderly as root caries is prevalent in institutionalized elders, emphasizing the need for effective prevention methods. A randomized trial performed in elders on root caries has shown that SDF solution, sodium fluoride varnish, and chlorhexidine varnish were more effective than Oral Hygiene Education (OHE) [82]. A controlled clinical trial investigating the aspects of preventing and arresting root caries among community dwelling elders showed that once a year application of SDF along with OHE every six months was effective in arresting root caries [83]. Gugnani $\mathrm{N}$ et al. [84] literature review showed that 38\% Silver diamine fluoride is effective in the prevention of root caries and recommended it as a "best choice" solution if professionally applied annually [84]. A randomized, double-blind, placebo-controlled clinical trial showed that SDF is simple, low-cost, and a promising intervention for arresting proximal surface caries [85]. A survey on the perceptions of SDF as a therapeutic agent for the treatment of dental caries [86] in underserved populations by registered dental hygienists showed that $85 \%$ of them felt it advantageous [87]. SDF is used to arrest and prevent new caries so that it maintains fixed and removable prostheses and supporting teeth cost-effectively in medically compromised, xerostomic, elderly patients. It is a medical management approach used successfully in those patients [88]. Homebound populations in the state of New Hampshire reported a positive experience and satisfaction with care received from certified public health dental hygienists using SDF [89]. Many systematic reviews evaluated the use of SDF for both root caries prevention and arrest in older adults showed the effective prevention and arrest in root caries, remineralization of deep occlusal lesions and treatment of hypersensitive dentin [90-95]. An in vitro study showed conditioning of teeth with 38\% SDF can increase the resistance of glass ionomer cement and composite restorations to secondary caries $[96,97]$. The use of SDF is rapid, inexpensive and non-threatening. It is suitable for treating frail elders, dementia patients exhibiting challenging behaviors and patients with multiple rapidly progressing decay [86,98-100]. A detailed guide for its application has been provided [101103]. SDF application positively influences enamel and dentine remineralization $[23,104]$. It showed improvement in the retention of a fissure sealant along with decreased microleakage and increased micro tensile bond strength of adhesives $[105,106]$.

\section{Disadvantages and contraindications associated with the application of SDF}

The use of SDF in anterior teeth remineralization makes it unsuitable due to staining [107]. Use of Potassium Iodide (KI) with SDF showed a lower intensity of discoloration than that occurred solely with SDF treatment $[108,109]$. The onset of black staining occurred within two minutes and increased up to six hours post-application of SDF irrespective of SDF concentrations [110]. Less staining of the carious dentine or surrounding enamel was noted when KI was used immediately after SDF [110,111]. Therefore, clinicians need to understand the staining effect of SDF and parental sensitivities for the use of SDF in pediatric patient's caries management $[42,112-115]$. A study on parental perceptions and acceptance of SDF use in Saudi Arabia showed the use of SDF was rejected due of staining. Clinicians are cautioned to provide proper informed consent along with clear photographs showing discolorations prior to treatment [116]. SDF use is contraindicated when immediate invasive action is required for the intended tooth like pain, infection, or sepsis, and where there is no readiness to change behaviors that lead to the development of the disease in the first place [117].

\section{Consensus on the use of SDF}

A national survey to assess U.S. pediatric dentists' education, knowledge, attitudes, and professional behavior for the use of SDF showed positive attitudes towards the use of SDF [118]. 31\% of the respondents used SDF often to arrest carious lesions in primary teeth, and $87 \%$ expected increased future use of SDF [118]. For restorations on children with behavioral issues, the medically frail or with severe dental anxiety SDF was regarded as an excellent treatment alterative [118]. A survey on the use of SDF in U.S. dental schools showed that SDF use is increasing rapidly in the U.S. and its adoption in most dental schools [119]. When esthetics is not a primary concern, SDF can prove to be a valuable tool in caries management [120]. Depth of visibility of the staining and the location of the cavities seem to play a major role in its acceptance [114]. In a scoping review on the esthetic perception, acceptability and satisfaction using SDF it was concluded that parents were satisfied with and found SDF acceptable [115,121,122]. Caregiver 
acceptance of SDF treatment was found to be high in a survey of caregiver acculturation and acceptance. The child's age and comfort of the caregiver play a prominent role in its approval [123,124]. U.S born caregivers had more approval than the non-U. S born caregivers [123]. Projection of economic impact study in the US showed that SDF is much more economical than the restorative treatment options in children among 1-5 years of age $[125,126]$. A novel intervention utilizing physician applied SDF in a primary care "Cavity Clinic" strategy in the US showed that it is feasible to prevent early childhood caries and suggested for partnership with an on-site hygienist but physician only sessions were still beneficial [127]. Determinants for implementation of SDF protocol include characteristics like the dental clinic's environment, the dental clinics themselves combined with the personality and training of dental staff [128].

\section{Conclusion}

SDF can be safely and effectively used to manage caries in primary dentition in children and the root caries in the elderly. In spite of the short comings in terms of esthetics, SDF has proven to be beneficial in caries management especially in populations having limited access to dental treatments such as in children who are difficult to manage or the elderly populations at the nursing homes. The recent pandemic has challenged the dental community in a multitude of ways and minimally invasive treatments were the only caries management options available for several months across the world. SDF was used as a major caries management technique during that period due to its efficacy and ease of use. Now more than ever a need has arisen to stabilize the carious lesions from progressing until comprehensive treatment can be performed. The authors encourage the members of the dental community to consider SDF as part of their caries management program due to its inherent advantages and its unique applicability to certain clinical situations.

\section{References}

1. Wong A, Subar PE, Young DA (2017) Dental Caries: An Update on Dental Trends and Therapy. Adv Pediatr 64(1): 307-330.

2. Duangthip D, Chen KJ, Gao SS, Lo ECM, Chu CH (2017) Managing Early Childhood Caries with Atraumatic Restorative Treatment and Topical Silver and Fluoride Agents. Int J Environ Res Public Health 14(10): 1024.

3. Chu CH, Lo ECM (2008) Promoting caries arrest in children with silver diamine fluoride: A review. Oral Health Prev Dent 6(4): 315-321.

4. Gao SS, Zhang S, Mei ML, Lo ECM, Chu CH (2016) Caries remineralization and arresting effect in children by professionally applied fluoride treatment-A systematic review. BMC Oral Health 16: 12.

5. Mei ML, Lo ECM, Chu CH (2016) Clinical Use of Silver Diamine Fluoride in Dental Treatment. Compend Contin Educ Dent Jamesburg NJ 1995 37(2): 93-98.

6. Croll TP, Berg JH (2018) Silver Diammine Fluoride: Rejuvination of a 172-Year-Old (or Older?) Dental Caries Attenuation. J Hist Dent 66(2): 54-61.
7. Burgess JO, Vaghela PM (2018) Silver Diamine Fluoride: A Successful Anticarious Solution with Limits. Adv Dent Res 29(1): 131-134.

8. Horst JA, Ellenikiotis H, Milgrom PM (2017) UCSF Protocol for Caries Arrest Using Silver Diamine Fluoride: Rationale, Indications and Consent. Pa Dent J (Harrisb) 4(1): 16-26.

9. Horst JA, Heima M (2019) Prevention of Dental Caries by Silver Diamine Fluoride. Compend Contin Educ Dent Jamesburg NJ 40(3): 158-163.

10. Nelson T, Scott JM, Crystal YO, Berg JH, Milgrom P (2016) Silver Diamine Fluoride in Pediatric Dentistry Training Programs: Survey of Graduate Program Directors. Pediatr Dent 38(3): 212-217.

11. Ruff RR, Niederman R (2018) Comparative effectiveness of treatments to prevent dental caries given to rural children in school-based settings: Protocol for a cluster randomised controlled trial. BMJ Open 8(4): e022646.

12. Ruff RR, Niederman R (2018) Silver diamine fluoride versus therapeutic sealants for the arrest and prevention of dental caries in low-income minority children: study protocol for a cluster randomized controlled trial. Trials 19(1): 523.

13. Rosenblatt A, Stamford TCM, Niederman R (2009) Silver diamine fluoride: a caries silver-fluoride bullet. J Dent Res 88(2): 116-125.

14. Seifo N, Robertson M, MacLean J, Blain K, Grosse S, et al. (2020) The use of Silver Diamine Fluoride (SDF) in dental practice. Br Dent J 228(2): 75-81.

15. Lin YS, Rothen ML, Milgrom P (2019) Pharmacokinetics of 38\% topical silver diamine fluoride in healthy adult volunteers. J Am Dent Assoc 150(3): 186-192.

16. Clemens J, Gold J, Chaffin J (2018) Effect and acceptance of silver diamine fluoride treatment on dental caries in primary teeth. J Public Health Dent 78(1): 63-68.

17. Canadian Agency for Drugs and Technologies in Health (2011) Silver Diamine Fluoride for the Prevention and Arresting of Dental Caries or Hypersensitivity: A Review. CADTH Report/Project in Briefs. Ottawa.

18. De Almeida L de FD, Cavalcanti YW, Valença AMG (2011) In vitro antibacterial activity of silver diamine fluoride in different concentrations. Acta Odontol Latinoam AOL 24(2): 127-131.

19. Garrastazu MD, Mathias Santamaria IF, Rocha RS, Diniz MB, Caneppele TMF, et al. (2020) Three Month Effect of Silver Diamine Fluoride (SDF) in Salivary Levels of Streptococcus Mutans in Children. An Exploratory Trial. Oral Health Prev Dent 22(2): 325-330.

20. Chu CH, Mei L, Seneviratne CJ, Lo ECM (2012) Effects of silver diamine fluoride on dentine carious lesions induced by Streptococcus mutans and Actinomyces naeslundii biofilms. Int J Paediatr Dent 22(1): 2-10.

21. Mei ML, Li Q Chu CH, Lo ECM, Samaranayake LP (2013) Antibacterial effects of silver diamine fluoride on multi-species cariogenic biofilm on caries. Ann Clin Microbiol Antimicrob 12: 4.

22. Mei ML, Chu CH, Low KH, Che CM, Lo ECM (2013) Caries arresting effect of silver diamine fluoride on dentine carious lesion with $S$. mutans and $L$. acidophilus dual-species cariogenic biofilm. Med Oral Patol Oral Cirugia Bucal 18(6): e824-831.

23. Mei ML, Ito L, Cao Y, Lo ECM, Li QL, et al. (2014) An ex vivo study of arrested primary teeth caries with silver diamine fluoride therapy. J Dent 42(4): 395-402.

24. Hamama HH, Yiu CK, Burrow MF (2015) Effect of silver diamine fluoride and potassium iodide on residual bacteria in dentinal tubules. Aust Dent J 60(1): 80-87.

25. Fakhruddin KS, Egusa H, Ngo HC, Panduwawala C, Pesee S, et al. (2020) Silver Diamine Fluoride (SDF) used in childhood caries management has potent antifungal activity against oral Candida species. BMC Microbiol 
20(1): 95.

26. Zhao IS, Mei ML, Li QL, Lo ECM, Chu CH (2017) Arresting simulated dentine caries with adjunctive application of silver nitrate solution and sodium fluoride varnish: An in-vitro study. Int Dent J 67(4): 206-214.

27. Zhao IS, Gao SS, Hiraishi N, Burrow MF, Duangthip D, et al. (2018) Mechanisms of silver diamine fluoride on arresting caries: A literature review. Int Dent J 68(2): 67-76.

28. Mei ML, Lo ECM, Chu CH (2018) Arresting Dentine Caries with Silver Diamine Fluoride: What's Behind It? J Dent Res 97(7): 751-758.

29. Mitwalli H, Mourao MDA, Dennison J, Yaman P, Paster BJ, et al. (2019) Effect of Silver Diamine Fluoride Treatment on Microbial Profiles of Plaque Biofilms from Root/Cervical Caries Lesions. Caries Res 53(5): 555-566.

30. Ishiguro T, Mayanagi G, Azumi M, Otani H, Fukushima A, et al. (2019) Sodium fluoride and silver diamine fluoride-coated tooth surfaces inhibit bacterial acid production at the bacteria/tooth interface. J Dent 84: 30-35.

31. Bimstein E, Damm D (2018) Human Primary Tooth Histology Six Months after Treatment with Silver Diamine Fluoride. J Clin Pediatr Dent 42(6):442-444

32. Mohammadi N, Farahmand Far MH (2018) Effect of fluoridated varnish and silver diamine fluoride on enamel demineralization resistance in primary dentition. J Indian Soc Pedod Prev Dent 36(3): 257-261.

33. Li Y, Liu Y, Psoter WJ, Nguyen OM, Bromage TG, et al. (2019) Assessment of the Silver Penetration and Distribution in Carious Lesions of Deciduous Teeth Treated with Silver Diamine Fluoride. Caries Res 53(4): 431-440.

34. Mei ML, Ito L, Cao Y, Li QL, Chu CH, et al. (2014) The inhibitory effects of silver diamine fluorides on cysteine cathepsins. J Dent 42(3): 329-335.

35. Rossi G, Squassi A, Mandalunis P, Kaplan A (2017) Effect of Silver Diamine Fluoride (SDF) on the dentin-pulp complex: Ex vivo histological analysis on human primary teeth and rat molars. Acta Odontol Latinoam AOL 30(1): 5-12.

36. Mei ML, Nudelman F, Marzec B, Walker JM, Lo ECM, et al. (2017) Formation of Fluorohydroxyapatite with Silver Diamine Fluoride. J Dent Res 96(10): 1122-1128.

37. Sinha N, Gupta A, Logani A, Shah N (2011) Remineralizing efficacy of silver diamine fluoride and glass ionomer type VII for their proposed use as indirect pulp capping materials - Part II (A clinical study). J Conserv Dent JCD 14(3): 233-236.

38. Quock RL, Patel SA, Falcao FA, Barros JA (2011) Is a drill-less dental filling possible? Med Hypotheses 77(3): 315-317.

39. Quock RL, Barros JA, Yang SW, Patel SA (2012) Effect of silver diamine fluoride on microtensile bond strength to dentin. Oper Dent 37(6): 610616.

40. Wu DI, Velamakanni S, Denisson J, Yaman P, Boynton JR, et al. (2016) Effect of Silver Diamine Fluoride (SDF) Application on Microtensile Bonding Strength of Dentin in Primary Teeth. Pediatr Dent 38(2): 148153.

41. McDonald SP, Sheiham A (1994) A clinical comparison of non-traumatic methods of treating dental caries. Int Dent J 44(5): 465-470.

42. Duangthip D, Fung MHT, Wong MCM, Chu CH, Lo ECM (2018) Adverse Effects of Silver Diamine Fluoride Treatment among Preschool Children. J Dent Res 97(4): 395-401.

43. Duangthip D, Gao SS, Chen KJ, Lo ECM, Chu CH (2019) Oral health-related quality of life of preschool children receiving silver diamine fluoride therapy: A prospective 6-month study. J Dent 81: 27-32.

44. Tirupathi S, Svsg N, Rajasekhar S, Nuvvula S (2019) Comparative cariostatic efficacy of a novel Nano-silver fluoride varnish with $38 \%$ silver diamine fluoride varnish a double-blind randomized clinical trial. J Clin Exp Dent 11(2): e105-112.

45. Lo EC, Chu CH, Lin HC (2001) A community-based caries control program for pre-school children using topical fluorides: 18-month results. J Dent Res 80(12): 2071-2074.

46. Chu CH, Lo ECM, Lin HC (2002) Effectiveness of silver diamine fluoride and sodium fluoride varnish in arresting dentin caries in Chinese preschool children. J Dent Res 81(11): 767-770.

47. Milgrom P, Horst JA, Ludwig S, Rotten M, Chaffee BW, et al. (2018) Topical silver diamine fluoride for dental caries arrest in preschool children: A randomized controlled trial and microbiological analysis of caries associated microbes and resistance gene expression. J Dent 68: 72-78.

48. Brignardello Petersen R (2018) Although silver diamine fluoride arrested caries sooner than fluoride varnish, the overall proportion of arrested caries was not importantly different after 30 months. J Am Dent Assoc 149(8): e117.

49. Llodra JC, Rodriguez A, Ferrer B, Menardia V, Ramos T, et al. (2005) Efficacy of silver diamine fluoride for caries reduction in primary teeth and first permanent molars of schoolchildren: 36-month clinical trial. J Dent Res 84(8): 721-724.

50. Yee R, Holmgren C, Mulder J, Lama D, Walker D, et al. (2009) Efficacy of silver diamine fluoride for Arresting Caries Treatment. J Dent Res 88(7): 644-647.

51. Zhi QH, Lo ECM, Lin HC (2012) Randomized clinical trial on effectiveness of silver diamine fluoride and glass ionomer in arresting dentine caries in preschool children. J Dent 40(11): 962-967.

52. Fung MHT, Duangthip D, Wong MCM, Lo ECM, Chu CH (2016) Arresting Dentine Caries with Different Concentration and Periodicity of Silver Diamine Fluoride. JDR Clin Transl Res 1(2): 143-152.

53. Brignardello Petersen R (2017) 37\% silver diamine fluoride is more effective than $12 \%$ silver diamine fluoride in arresting caries in the primary dentition. J Am Dent Assoc 148(12): e205.

54. Brignardello Petersen R (2019) Silver diamine fluoride seems to be effective in preventing and arresting root caries in older adults compared with placebo, but there is very low certainty in the magnitude of the benefit. J Am Dent Assoc 150(1): e3.

55. Fung MHT, Duangthip D, Wong MCM, Lo ECM, Chu CH (2018) Randomized Clinical Trial of $12 \%$ and 38\% Silver Diamine Fluoride Treatment. J Dent Res 97(2): 171-178.

56. Gao SS, Duangthip D, Wong MCM, Lo ECM, Chu CH (2019) Randomized Trial of Silver Nitrate with Sodium Fluoride for Caries Arrest. JDR Clin Transl Res 4(2): 126-134.

57. Vollú AL, Rodrigues GF, Rougemount Teixeira RV, Cruz LR, et al. (2019) Efficacy of $30 \%$ silver diamine fluoride compared to atraumatic restorative treatment on dentine caries arrestment in primary molars of preschool children: A 12-months parallel randomized controlled clinical trial. J Dent 88: 103165.

58. Gao SS, Chen KJ, Duangthip D, Wong MCM, Lo ECM, et al. (2020) Preventing early childhood caries with silver diamine fluoride: Study protocol for a randomised clinical trial. Trials 21(1): 140.

59. Deery C (2009) Silver lining for caries cloud? Evid Based Dent 10(3): 68.

60. Sharma G, Puranik MP, KRS (2015) Approaches to Arresting Dental Caries: An Update. J Clin Diagn Res JCDR 9(5): ZE08-11.

61. Hu S, Meyer B, Duggal M (2018) A silver renaissance in dentistry. Eur Arch Paediatr Dent Off J Eur Acad Paediatr Dent 19(4): 221-227.

62. Seifo N, Cassie H, Radford JR, Innes NPT (2019) Silver diamine fluoride for managing carious lesions: An umbrella review. BMC Oral Health 19(1): 145 . 
63. Schmoeckel J, Gorseta K, Splieth CH, Juric H (2020) How to Intervene in the Caries Process: Early Childhood Caries-A Systematic Review. Caries Res: 1-11.

64. Tedesco TK, Gimenez T, Floriano I, Montagner AF, Camargo LB, et al. (2018) Scientific evidence for the management of dentin caries lesions in pediatric dentistry: A systematic review and network meta-analysis. PloS One 13(11): e0206296.

65. Gao SS, Zhao IS, Hiraishi N, Duangthip D, Mei ML, et al. (2016) Clinical Trials of Silver Diamine Fluoride in Arresting Caries among Children: A Systematic Review. JDR Clin Transl Res 1(3): 201-210.

66. Richards D (2017) The effectiveness of silver diamine fluoride in arresting caries. Evid Based Dent 18(3): 70.

67. Gold J (2017) Limited Evidence Links Silver Diamine Fluoride and Caries Arrest in Children. J Evid-Based Dent Pract 17(3): 265-267.

68. Chibinski AC, Wambier LM, Feltrin J, Loguercio AD, Wambier DS, et al. (2017) Silver Diamine Fluoride Has Efficacy in Controlling Caries Progression in Primary Teeth: A Systematic Review and Meta-Analysis. Caries Res 51(5): 527-541.

69. Gugnani N, Gugnani S (2017) Remineralization and arresting caries in children with topical fluorides. Evid Based Dent 18(2): 41-42.

70. Trieu A, Mohamed A, Lynch E (2019) Silver diamine fluoride versus sodium fluoride for arresting dentine caries in children: A systematic review and meta-analysis. Sci Rep 9(1): 2115.

71. Oliveira BH, Rajendra A, Veitz Keenan A, Niederman R (2019) The Effect of Silver Diamine Fluoride in Preventing Caries in the Primary Dentition: A Systematic Review and Meta-Analysis. Caries Res 53(1): 24-32.

72. Urquhart O, Tampi MP, Pilcher L, Slayton RL, Araujo MWB, et al. (2019) Nonrestorative Treatments for Caries: Systematic Review and Network Meta-analysis. J Dent Res 98(1): 14-26.

73. Beltrán Aguilar ED (2010) Silver Diamine Fluoride (SDF) may be better than fluoride varnish and no treatment in arresting and preventing cavitated carious lesions. J Evid-Based Dent Pract 10(2): 122-124

74. Crystal YO, Niederman R (2016) Silver Diamine Fluoride Treatment Considerations in Children's Caries Management. Pediatr Dent 38(7): 466-471.

75. Yeung SST, Argáez C (2017) Silver Diamine Fluoride for the Prevention and Arresting of Dental Caries or Hypersensitivity: A Review of Clinical Effectiveness, Cost-Effectiveness and Guidelines. Ottawa (ON): Canadian Agency for Drugs and Technologies in Health.

76. Crystal YO, Marghalani AA, Ureles SD, Wright JT, Sulyanto R, et al. (2017) Use of Silver Diamine Fluoride for Dental Caries Management in Children and Adolescents, Including Those with Special Health Care Needs. Pediatr Dent 39(5): 135-145.

77. Seifo N, Al Yaseen W, Innes N (2018) The efficacy of silver diamine fluoride in arresting caries in children. Evid Based Dent 19(2): 42-43.

78. Devji T (2018) Silver diamine fluoride is probably more effective than atraumatic restorative treatment, fluoride varnish, or no treatment for controlling caries progression in children. J Am Dent Assoc 149(4): e65.

79. Hammersmith KJ, DePalo JR, Casamassimo PS, MacLean JK, Peng J (2020) Silver Diamine Fluoride and Fluoride Varnish May Halt Interproximal Caries Progression in the Primary Dentition. J Clin Pediatr Dent 44(2): 79-83.

80. Chu CH, Lee AHC, Zheng L, Mei ML, Chan GCF (2014) Arresting rampant dental caries with silver diamine fluoride in a young teenager suffering from chronic oral graft versus host disease post-bone marrow transplantation: A case report. BMC Res Notes 7:3.

81. Crystal YO, Rabieh S, Janal MN, Rasamimari S, Bromage TG (2019) Silver and fluoride content and short-term stability of $38 \%$ silver diamine fluoride. J Am Dent Assoc 150(2): 140-146.
82. Tan HP, Lo ECM, Dyson JE, Luo Y, Corbet EF (2010) A randomized trial on root caries prevention in elders. J Dent Res 89(10): 1086-1090.

83. Zhang W, McGrath C, Lo ECM, Li JY (2013) Silver diamine fluoride and education to prevent and arrest root caries among community-dwelling elders. Caries Res 47(4): 284-290.

84. Gluzman R, Katz RV, Frey BJ, McGowan R (2013) Prevention of root caries: a literature review of primary and secondary preventive agents. Spec Care Dent Off Publ Am Assoc Hosp Dent Acad Dent Handicap Am Soc Geriatr Dent 33(3): 133-140.

85. Mattos Silveira J, Floriano I, Ferreira FR, Viganó MEF, Frizzo MA, et al. (2014) New proposal of silver diamine fluoride use in arresting approximal caries: Study protocol for a randomized controlled trial. Trials 15: 448.

86. Deutsch A (2016) An alternate technique of care using silver fluoride followed by stannous fluoride in the management of root caries in aged care. Spec Care Dent Off Publ Am Assoc Hosp Dent Acad Dent Handicap Am Soc Geriatr Dent 36(2): 85-92.

87. Chhokar SK, Laughter L, Rowe DJ (2017) Perceptions of Registered Dental Hygienists in Alternative Practice Regarding Silver Diamine Fluoride. J Dent Hyg JDH 91(4): 53-60.

88. Giusti L, Steinborn C, Steinborn M (2018) Use of silver diamine fluoride for the maintenance of dental prostheses in a high caries-risk patient: A medical management approach. J Prosthet Dent 119(5): 713-716.

89. Crete P, Boyd LD, Fitzgerald JK, LaSpina LM (2018) Access to Preventive Oral Health Services for Homebound Populations: A pilot program. J Dent Hyg JDH 92(6): 24-32.

90. Hendre AD, Taylor GW, Chávez EM, Hyde S (2017) A systematic review of silver diamine fluoride: Effectiveness and application in older adults. Gerodontology 34(4): 411-419.

91. McReynolds D, Duane B (2018) Systematic review finds that silver diamine fluoride is effective for both root caries prevention and arrest in older adults. Evid Based Dent 19(2): 46-47.

92. Oliveira BH, Cunha Cruz J, Rajendra A, Niederman R (2018) Controlling caries in exposed root surfaces with silver diamine fluoride: A systematic review with meta-analysis. J Am Dent Assoc 149(8): 671-679.

93. Meyer Lueckel H, Machiulskiene V, Giacaman RA (2019) How to Intervene in the Root Caries Process? Systematic Review and MetaAnalyses. Caries Res 53(6): 599-608.

94.Gold J (2019) Silver Diamine Fluoride May Prevent and Arrest Root Caries in Older Adults. J Evid-Based Dent Pract 19(2): 186-188.

95. Zhang J, Sardana D, Li KY, Leung KCM, Lo ECM (2020) Topical Fluoride to Prevent Root Caries: Systematic Review with Network Meta-analysis. J Dent Res 99(5): 506-513.

96.Zhao IS, Mei ML, Burrow MF, Lo ECM, Chu CH (2017) Prevention of secondary caries using silver diamine fluoride treatment and casein phosphopeptide-amorphous calcium phosphate modified glassionomer cement. J Dent 57: 38-44.

97. Mei ML, Zhao IS, Ito L, Lo ECM, Chu CH (2016) Prevention of secondary caries by silver diamine fluoride. Int Dent J 66(2): 71-77.

98. Schwendicke F, Göstemeyer G (2017) Cost-effectiveness of root caries preventive treatments. J Dent 56: 58-64.

99. Wright JT, White A (2017) Silver Diamine Fluoride: Changing the Caries Management Paradigm and Potential Societal Impact. N C Med J 78(6): 394-397.

100. Yasmi O Crystal, Abdullah A Marghalani, Steven D Ureles, John Timothy Wright, Rosalyn Sulyanto, et al. (2017) Use of Silver Diamine Fluoride for Dental Caries Management in Children and Adolescents, Including Those with Special Health Care Needs. Pediatr Dent 39(5): 135-145. 
101. Chairside Guide (2018) Silver Diamine Fluoride in the Management of Dental Caries Lesions. Pediatr Dent 40(6): 492-517.

102. Slayton RL, Urquhart O, Araujo MWB, Fontana M, Guzmán Armstrong $S$, et al. (2018) Evidence-based clinical practice guideline on nonrestorative treatments for carious lesions: A report from the American Dental Association. J Am Dent Assoc 149(10): 837-849.

103. Burgette JM, Weintraub JA, Birken SA, Lewis TA, White BA (2019) Development of a Silver Diamine Fluoride Protocol in Safety Net Dental Settings. J Dent Child Chic 86(1): 32-39.

104. Yu OY, Mei ML, Zhao IS, Li QL, Lo ECM, et al. (2018) Remineralization of enamel with silver diamine fluoride and sodium fluoride. Dent Mater Off Publ Acad Dent Mater 34(12): 344-352.

105. Pérez Hernández J, Aguilar Díaz FC, Venegas Lancón RD, Gayosso CAÁ, Villanueva Vilchis MC, et al. (2018) Effect of silver diamine fluoride on adhesion and microleakage of a pit and fissure sealant to tooth enamel: in vitro trial. Eur Arch Paediatr Dent Off J Eur Acad Paediatr Dent 19(6):411-416.

106. Siqueira FSF de, Morales LAR, Granja MCP, De Melo B de O, Monteiro Neto V, et al (2020) Effect of Silver Diamine Fluoride on the Bonding Properties to Caries-affected Dentin. J Adhes Dent 22(2): 161-172.

107. Nantanee R, Santiwong B, Trairatvorakul C, Hamba H, Tagami J (2016) Silver diamine fluoride and glass ionomer differentially remineralize early caries lesions, In situ. Clin Oral Investig 20(6): 1151-1157.

108. Zhao IS, Mei ML, Burrow MF, Lo ECM, Chu CH (2017) Effect of Silver Diamine Fluoride and Potassium Iodide Treatment on Secondary Caries Prevention and Tooth Discoloration in Cervical Glass Ionomer Cement Restoration. Int J Mol Sci 18(2): 340.

109. Garg S, Sadr A, Chan D (2019) Potassium Iodide Reversal of Silver Diamine Fluoride Staining: A Case Report. Oper Dent 44(3): 221-226.

110. Patel J, Anthonappa RP, King NM (2018) Evaluation of the staining potential of silver diamine fluoride: In vitro. Int J Paediatr Dent.

111. Zhao IS, Chu S, Yu OY, Mei ML, Chu CH, et al. (2019) Effect of silver diamine fluoride and potassium iodide on shear bond strength of glass ionomer cements to caries-affected dentine. Int Dent J 69(5): 341-347.

112. Crystal YO, Janal MN, Hamilton DS, Niederman R (2017) Parental perceptions and acceptance of silver diamine fluoride staining. J Am Dent Assoc 148(7): 510-518.

113. Gordon NB (2018) Silver Diamine Fluoride Staining is Acceptable for Posterior Primary Teeth and Is Preferred Over Advanced Pharmacologic Behavior Management by Many Parents. J Evid-Based Dent Pract 18(1): 94-97.

114. Crystal YO, Kreider B, Raveis VH (2019) Parental Expressed Concerns about Silver Diamine Fluoride (SDF) Treatment. J Clin Pediatr Dent 43(3): 155-160.

115. Magno MB, Silva LP da, Ferreira DM, Barja Fidalgo F, Fonseca Gonçalves A (2019) Aesthetic perception, acceptability and satisfaction in the treatment of caries lesions with silver diamine fluoride: A scoping review. Int J Paediatr Dent 29(3): 257-266.

116. Alshammari AF, Almuqrin AA, Aldakhil AM, Alshammari BH, Lopez JNJ (2019) Parental perceptions and acceptance of silver diamine fluoride treatment in Kingdom of Saudi Arabia. Int J Health Sci 13(2): 25-29.

117. Van Strijp G, Van Loveren C (2018) No Removal and Inactivation of Carious Tissue: Non-Restorative Cavity Control. Monogr Oral Sci 27: 124-136.

118. Antonioni MB, Fontana M, Salzmann LB, Inglehart MR (2019) Pediatric Dentists' Silver Diamine Fluoride Education, Knowledge, Attitudes, and Professional Behavior: A National Survey. J Dent Educ 83(2): 173182.

119. Ngoc CN, Mehta R, Donovan TE, Ferreira Zandona AG (2018) Teaching Silver Diamine Fluoride in U.S. Dental Schools' Predoctoral Curricula. J Dent Educ 82(12): 1245-1246.

120. Crystal YO, Niederman R (2019) Evidence-Based Dentistry Update on Silver Diamine Fluoride. Dent Clin North Am 63(1): 45-68.

121. Bagher SM, Sabbagh HJ, AlJohani SM, Alharbi G, Aldajani M, et al. (2019) Parental acceptance of the utilization of silver diamine fluoride on their child's primary and permanent teeth. Patient Prefer Adherence 13: 829-835.

122. Huebner CE, Milgrom P, Cunha Cruz J, Scott J, Spiekerman C, et al. (2020) Parents' Satisfaction with Silver Diamine Fluoride Treatment of Carious Lesions in Children. J Dent Child Chic 87(1) :4-11.

123. Kumar A, Cernigliaro D, Northridge ME, Wu Y, Troxel AB, et al. (2019) A survey of caregiver acculturation and acceptance of silver diamine fluoride treatment for childhood caries. BMC Oral Health 19(1): 228.

124. Cernigliaro D, Kumar A, Northridge ME, Wu Y, Troxel AB, et al. (2019) Caregiver satisfaction with interim silver diamine fluoride applications for their children with caries prior to operating room treatment or sedation. J Public Health Dent 79(4): 286-291.

125. Johhnson B, Serban N, Griffin PM, Tomar SL (2019) Projecting the economic impact of silver diamine fluoride on caries treatment expenditures and outcomes in young U.S. children. J Public Health Dent 79(3): 215-221.

126. Warren JJ, Thrap S, Starr D (2020) Dental caries treatment completed under general anesthesia among American Indian children in a northern plain's tribal community. J Public Health Dent.

127. Bernstein RS, Johnston B, Mackay K, Sanders J (2019) Implementation of a primary care physician-led Cavity Clinic using silver diamine fluoride. J Public Health Dent 79(3): 193-197.

128. Weintraub JA, Birken SA, Burgette JM, Lewis TA, White BA (2019) Use of the consolidated framework for implementation research to assess determinants of silver diamine fluoride implementation in safety net dental clinics. J Public Health Dent 79(4): 298-306. 


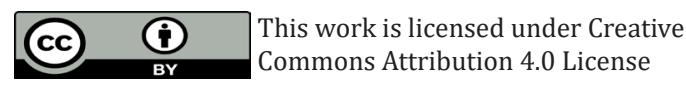

To Submit Your Article Click Here:

DoI: 10.32474/MADOHC.2020.04.000191

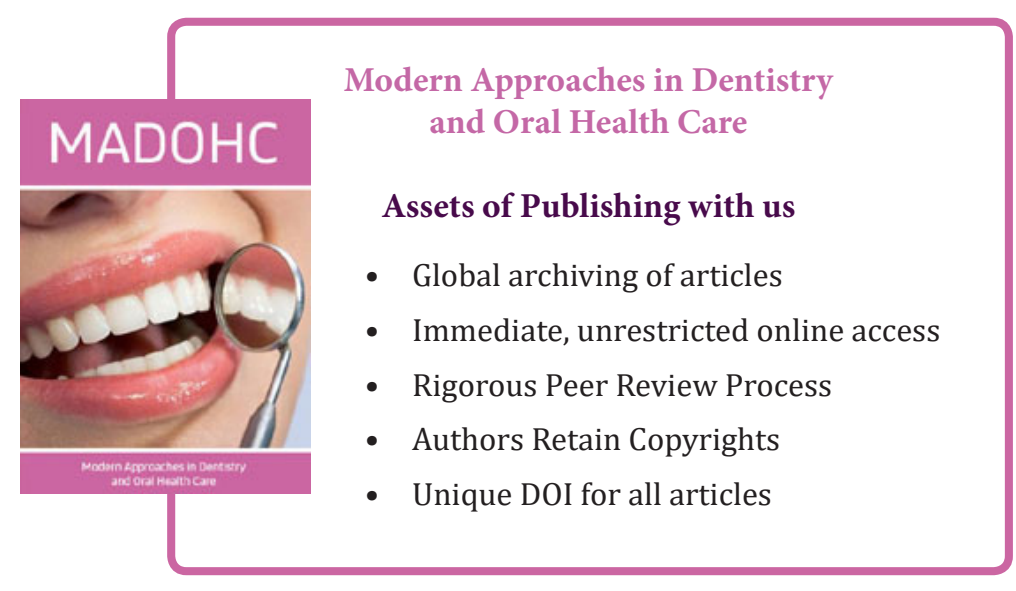

